\title{
DO DIREITO À CIDADE AO FAZER-CIDADE. O ANTROPÓLOGO, A MARGEM E O CENTRO*
}

Michel Agier

Para introduzir esta reflexão, eu devo dizer logo de saída que o vínculo que será estabelecido aqui entre etnografia das margens e antropologia da cidade não pretende reproduzir a oposição radical ou mesmo "ontológica" entre a marginalidade e a centralidade em si. Muito ao contrário, eu pretendo descrever uma dinâmica, uma dialética, uma relação necessária e, por fim, certa continuidade entre uma e outra. Mais profundamente, eu desejo implementar um método que permita pensar a universalidade da cidade fora de qualquer pretensão normativa, ou seja, segundo uma concepção ao mesmo tempo epistemológica e política. Baseada em pesquisa etnográfica urbana, esta concepção defende a ideia de uma construção/ desconstrução de seu objeto "cidade", rejeitando qualquer definição a priori da mesma enquanto ferramenta analítica. A questão seria antes: o que faz e desfaz a cidade permanentemente? Ela conduz à divulgação de processos e portanto à política que impulsiona o movimento necessário à sua existência, às suas reprodução e transformação.

A cidade é um "objeto virtual", escrevia Henri Lefebvre em Le droit à la ville, no início de 1968 (Lefebvre 2009:97). Esta afirmação foi em seguida verificada, indiretamente, na constatação de que o urbano ultrapassava a cidade: o filósofo, por extrapolação da cidade existente, antecipava o nascimento de uma sociedade "completamente urbana" tanto quanto planetária (Lefebvre 1970). Isto conferiu mais força teórica e política à ideia de uma virtualidade da cidade. Mais recentemente, o geógrafo David Harvey observava, após Lefebvre, que o "direito à cidade" aponta no fundo para "alguma coisa que já não existe"; é um "significante vazio", ele escreve, "tudo depende de quem lhe conferirá sentido" (Harvey 2011:42). Como em eco, podemos observar que os atores dos movimentos sociais desta última década, que reclamam o "direito à cidade", não leram necessariamente a obra de Henry Lefebvre... mas fizeram deste apelo um horizonte de sua 
ação em meio urbano e transformando o urbano. Neste sentido, o que me parece possível descrever, ao estudar o "fazer-cidade" dos citadinos, é de que, de qual sentido e de que matéria é preenchido este significante vazio denominado "direito à cidade". E a resposta que eu proponho é a seguinte: a cidade é feita essencialmente de movimento.

O princípio de relatividade pode ser aplicado à dinâmica urbana como a todos os objetos da ciência social. Ele nos permite evitar os pensamentos normativos que, por sua vez, tendem a congelar as dinâmicas sociais. De fato, para o universo urbano, assim como para o universo em geral, podemos evocar simultaneamente a relatividade no espaço (ela pode ser observada quando postulamos a igualdade espistemológica entre todas as formas urbanas assim como entre todas as culturas) e a relatividade no tempo (as cidades nascem, transformam-se ou desaparecem, como o demonstram sobre este último aspecto as histórias de Detroit ou Filadélfia). Se a antropologia pode e tem todo o interesse em se apoiar nesta teoria da relatividade urbana no tempo e no espaço, é porque a dinâmica e a transformação podem ser reconhecidas em um saber livre de amarras políticas, normativas e institucionais, como é o saber antropológico. São portanto a descrição e a compreensão do movimento permanente de transformação urbana no tempo e no espaço que podem constituir a contribuição do olhar antropológico sobre a cidade.

Este movimento é o de "fazer-cidade". Ele é incitado por uma ausência ("a cidade está morta", escrevia Lefebvre) e é impulsionado por uma imagem: um mito perdido, um horizonte inatingível. De fato, não temos senão cidades ideais ou cidades de ficção científica, dizia ainda Lefebvre (2009:110) e, segundo o filósofo da cidade Jean-Christophe Bailly, nós vemos por trás de qualquer cidade o "fantasma de um ideal perdido". Da perda provém a potência da virtualidade da cidade, horizonte de um "apelo" e de uma "exigência" (Lefebvre 2009:107). Horizonte aberto, é o movimento permanente do "fazer-cidade" que pode nos permitir encontrar alguma coisa da cidade que observamos nas experiências concretas do espaço.

\section{Epistemologia do fazer-cidade}

"Coisa humana por excelência", a cidade é a "forma mais complexa e refinada da civilização", escrevia Lévi-Strauss, mas ela lhe parecia ser também o lugar de uma individualização extrema e de um borramento dos limites sociais, atingindo o inapreensível caos. ${ }^{1}$ Multitude sem totalidade, a cidade seria heterogênea demais para que o etnólogo conseguisse aceder à sua complexidade sem se perder... ainda que seja também para ele, ocidental 
que realiza seu trabalho de campo em lugares "exóticos", o local em que mantém sua vida privada, seu local de repouso. No melhor dos casos, a cidade poderia ser - segundo as palavras irônicas que Lévi-Strauss utilizou para seus próprios comentários sobre São Paulo, onde viveu de 1935 a 1939 o lugar para uma "etnografia de domingo" (apud Magnani 1999).

No entanto, esta abordagem etnográfica, fundada sobre a pesquisa relacional, local e "micrológica" que pareceu justificar a suposta incompatibilidade entre a antropologia e a cidade imensa, complexa e impenetrável, é precisamente aquela que torna possível, do meu ponto de vista, a elaboração de uma antropologia da cidade.

Meu argumento é epistemológico: é a relação de construção e desconstrução entre o campo de pesquisa e o objeto de pesquisa que torna possível um olhar antropológico sobre a cidade. Dito de outro modo, a resposta à questão de saber se uma antropologia da cidade é possível se encontra no coração mesmo do modo de conhecimento da antropologia, que constrói e desconstrói seus objetos de pesquisa a partir de sua maneira particular, empírica, relacional e reflexiva de apreender o "campo". Em primeiro lugar, porque esta abordagem permite descrever a cidade do interior por aquela ou aquele que está implicada(o). "Eu só observo situações", escrevia Jean Bazin a propósito da pesquisa antropológica em geral, e precisava a propósito da "sociedade" (o que pode ser dito também a propósito da "cidade"): "Não é uma coisa que eu possa observar". Por mais distante ou pequena que ela seja, o ponto de vista de Sirius não me é acessível" (Bazin 1996). Minha própria abordagem deve muito às reflexões formuladas de maneira pioneira por Gérard Althabe, segundo as quais a situação de pesquisa e de comunicação vivenciada pelo etnógrafo é o que funda o ponto de vista antropológico sobre a cidade - o "lugar" de onde se fala — , o que restitui toda a potência analítica ao caráter relativo e subjetivo da etnografia. ${ }^{2}$

Podemos até mesmo reverter a nosso proveito o desconcerto dos urbanistas, dos sociólogos e de outros experts em estudos urbanos e em política da cidade, segundo os quais a cidade se desfaz, diluindo-se no exterior até o urbano "desterritorializado" e planetário, e fragmentando-se em seu seio segundo os princípios de um novo "urbanismo por afinidade" (Donzelot 1999). ${ }^{3}$ Podemos opor a este desconcerto as questões e a abordagem da antropo-lógica das cidades, já que buscam compreender a gênese e o processo da cidade em geral. Elas visam descrever os começos da cidade por toda parte onde ocorrem. Assim, a compreensão das cidades terá muito a ganhar ao se dirigir não mais somente ao que se perde nos espaços da "não cidade", ${ }^{4}$ mas também ao que nasce ali mesmo, como expressão de uma dialética mais geral do vazio e do pleno, do fraco e do forte. 
Nesta pesquisa necessária, a exemplaridade das antropologias enraizadas no campo e sensíveis aos processos pode ser mais eficaz que a "representatividade" dos dados estatísticos que dependem de definições $a$ priori externas, globais e normativas do que é - e do que não é - a cidade. Dito de outro modo, há lugar, diante desta cidade "desfeita" e neste momento de crise urbana, para a imaginação e a representação de uma cidade que seja o resultado da descrição da cidade pelo antropólogo, e que tenha alguma chance de ser mais verdadeira que aquela produzida ou levada em consideração pelas abordagens quantitativas, as representações gráficas e as políticas urbanas. É o que denominei cidade bis, ideia que não é estranha àquela das "cidades invisíveis" de Italo Calvino, enquanto ferramenta crítica do "realismo sociológico" dos experts da cidade, ou seja, da crença de que a cidade é uma coisa dada que se confunde com a realidade de tudo que se passa ali. Ao falar em cidade bis, eu quis dizer que era possível "desenhar" uma cidade múltipla, partindo do ponto de vista das práticas, das relações e das palavras dos citadinos tais como o próprio pesquisador as observa, as coleta e anota, direta e situacionalmente, e que esta cidade não é menos real que aquela dos urbanistas ou dos administradores. É outra.

Partirei, portanto, da forma indutiva do raciocínio antropológico, que vai do campo à teoria. Em qualquer pesquisa etnográfica, todo objeto se define por um limite, que o distingue de um exterior e o faz existir. De modo mais geral, é sempre sobre uma fronteira existente, na qual ganha sentido a relação entre identidade e alteridade, que o "outro" começa a existir para "mim" ou para "nós". Podemos estender este princípio e considerar que o lugar da fronteira, descentrado, é o quadro privilegiado para se observar e compreender a existência de qualquer coisa. ${ }^{5}$ Se a cidade é um conjunto de "coisas" (edifícios, bens, relações, agrupamentos, textos...) difíceis de definir como "essencialmente" urbanos, este conjunto procede de limites ou fronteiras que o cirscunscrevem e a partir dos quais ele comença a existir. Contudo, se quisermos ser coerentes com esta concepção relativa, devemos precisar de saída que as delimitações e as caracterizações de cada cidade estudada em um dado momento não são nem eternas, nem definitivas.

Esta atenção à constituição de qualquer coisa por seu limite me leva logicamente a apreender a cidade a partir do vazio deixado por sua não existência, a partir de seu limite, de sua negação, de seu exterior e de sua margem: "o menos longínquo de todos os alhures", segundo a bela fórmula do filósofo da cidade Jean-Christophe Bailly a propósito da periferia na França (Bailly 2013). É o ponto de observação ideal do movimento e da passagem de um estado a outro, de um ambiente ou de uma condição a outra. É o que me conduz a considerar que a etnografia das "margens" ou dos 
limites é o método ideal para uma antropologia da cidade. Não a margem como fato social, geográfico ou cultural, mas a margem como posição epistemológica e política: apreender o limite do que existe - e que existe sob a aparência oficial e afirmada do realizado, do estabelecido, do ordenado, central e dominante - permite perceber a dialética do vazio e do cheio e descrever o que, a partir de quase nada ou de um estado aparentemente caótico, faz cidade.

\section{Um objeto exemplar, mas precário: o fazer-cidade dos citadinos sem cidade}

A partir de pesquisas etnográficas realizadas na África e na América Latina, interesso-me por diferentes aspectos desta questão: a fundação da cidade desde as margens urbanas - bairros populares ou "invasões", estabelecimentos provisórios de migrantes, campos de refugiados - ou, para dizer de modo mais geral, interesso-me por pensar a cidade a partir dos espaços precários e de um certo despojamento de bens, de sentidos e de relações.

Existem múltiplas maneiras de se fazer cidade. Múltiplos processos nos falam sobre um começo de cidade em geral, como aquele que me pareceu possível evidenciar ao observar os campos de refugiados que considerei como "rascunhos de cidade" (Agier 2011).

Detenhamo-nos um instante sobre o caso dos acampamentos de estrangeiros de Patras, na Grécia, e de Calais, no norte da França, duas cidades portuárias nas quais os migrantes estabeleceram acampamentos que ficaram de pé por 12 anos, no primeiro caso, e por seis anos, no segundo, antes de sua destruição pela polícia em julho e setembro de $2009 .{ }^{6}$ Com o tempo, o que emerge do interior desses locais precários, no lugar das primeiras tendas e toldos emergenciais, são porções de cidade feitas de tela, sucata e madeira. Tábuas de madeira ou gradis de arame roubados próximo ao porto servem para fabricar as estruturas das cabanas. Estrados de madeira são dispostos sobre o solo para isolar as tábuas, enquanto as paredes são isoladas graças a placas de poliestireno dispostas lado a lado; o restante destas "paredes" é feito de toldos de plástico e de papelão. Pedaços de carpete encontrados pelas ruas se tornam tapetes, e patchworks de tecidos e de cobertores servem de cortina.

São citadinos ordenadores que aparecem nesses lugares nascidos como refúgios, abrigos ou esconderijos no coração da Europa. O que fazem se parece com o que denominamos, nos bairros periféricos da África, da Ásia ou da América Latina, bairros "espontâneos", "informais" ou em "au- 
toconstrução": as práticas e os saberes aprendidos e experimentados nas situações sociais precárias são comparáveis. A partir da matéria-prima disponível (terra, água, madeira da floresta) ou da matéria residual de produtos manufaturados (tábuas de madeira, estrados de madeira, toldos de plástico, tecidos de sacolas, folhas metálicas de embalagens, placas de poliestireno etc.) uma arquitetura dos acampamentos se desenvolve, como, aliás, uma arquitetura das favelas ou dos bidonvilles.

Paradoxo desses "locais fora de lugar" (hors lieux), ao mesmo tempo frágeis localmente, eles se estabilizam em uma dimensão supralocal. Assim, após 12 anos de existência, o acampamento de Patras tornou-se um ponto de referência para os migrantes, um ponto fixo em suas múltiplas rotas. Patras é conhecida de todos aqueles que tentam essas rotas, bem como o são Zahedan (na fronteira entre o Irã, o Paquistão e o Afeganistão), Calais (no norte da França), Roma (ver Mazzitelli 2012) ou a Gare de l'Est em Paris. Estes locais tornaram-se, em parte, cruzamentos cosmopolitas: são as etapas do percurso que têm o mundo como escala, um percurso sempre arriscado, imprevisível que vai agora do Afeganistão (ou do Paquistão, ou do Irã) à Europa, mas o exílio pode mudar de perímetro. É o caso do exílio africano que se dirige principalmente à Europa (via Mediterrâneo ou leste da Europa), mas que tende a se orientar, recentemente, em direção ao Oriente Próximo, à América Latina e à Ásia, criando assim novas rotas e novos locais-etapas nestes novos percursos.

Estes pontos de referência cosmopolitas nos percursos transnacionais são também bastante locais e o são duplamente. Se eu me refiro a Patras e a Calais, posso observar, antes de mais nada, que eles têm vários anos de existência: uma pátina foi feita, recém-chegados encontraram habitats que já estavam lá, já construídos e "habitados" e se inseriram como nos inserimos em um "lugar antropológico" (Augé 1992). Este último já tem um pouco de história (12 anos de existência em Patras, quase sete anos em Calais), algumas relações internas (amizades tecidas e desenvolvidas nos momentos de espera, mas também rivalidades e tensões em Patras com os curdos iraquianos ou sudaneses). Ele tem também uma identidade externa (em Calais, é denominado "a floresta dos afegãos", na Grécia, "o acampamento de Patras"). Por fim, estes estabelecimentos já fazem parte da história das cidades nas quais nasceram: histórias de conflitos e de solidariedades tanto em Patras como em Calais.

Quando os conflitos colocam em cena habitantes das cidades de chegada, autodenominados "ribeirinhos" ou "autóctones", assim como as autoridades administrativas, os apoios provêm de outros habitantes e de associações destas cidades, que podem ser humanitárias, jurídicas ou políticas. Assim, o 
acampamento de Patras deve seus 12 anos de existência (de finais de 1996 até a sua destruição pelo fogo e as retro-escavadeiras em julho de 2009) à persistência de uma "tolerância" municipal, resultado de um acordo entre a pressão de certos nativos pouco acolhedores, as associações de defesa dos direitos dos estrangeiros e os migrantes em busca de uma via para um porto/ fronteira e instalados no acampamento. Apesar do importante turn over dos ocupantes, alguns puderam se estabelecer ali por até dois anos, abrindo uma loja de restauração, de produtos de primeira necessidade, trabalhando ocasionalmente nos laranjais vizinhos ou ainda ocupando posições de liderança. Mahmoud é apresentado como "líder" do acampamento. Sua formação é de assistente social, mas lá, na migração, ele circula entre Patras e Atenas. Ele é o proprietário de uma das duas lojas do acampamento. Ele nos diz: "Patras é uma cidade fora da lei".

Diferentemente desses acampamentos que encontramos nas fronteiras e nos interstícios das cidades, alguns campos de refugiados são mais estabilizados e duram várias décadas (Agier 2014a). Nestes casos, é a forma dos campos-cidades que emerge. A abordagem que adotei para lidar com esses "locais fora de lugar" (hors lieux) é a de uma etnografia urbana dos acampamentos. Aqui também a questão não tem qualquer conteúdo normativo ou evolucionista. Procuro dar conta das criações sociais, mudanças culturais e eventualmente de novas formas políticas que aparecem, a partir do momento em que as pessoas se encontram reunidas por um tempo indefinido em um dado espaço, qualquer que seja ele, e que pode ser considerado como uma "implantação relativamente permanente e densa de indivíduos heterogêneos", segundo os termos utilizados por Louis Wirth para definir a cidade nos anos 1930 (Wirth 1984). Procuro também compreender as transformações do espaço que esta situação implica: um acampamento que tem cinco anos de existência já não é mais um alinhamento de tendas, ele pode se assemelhar tanto a um imenso bidonville como pode fazer pensar em um museu etnográfico onde cada um tenta, com os materiais que encontra por ali, reconstituir o melhor possível seu habitat de origem. O resultado é, por vezes, uma paisagem híbrida, os toldos de cor azul e branca da $\mathrm{UNHCR}^{7}$ recobrindo as frágeis construções feitas de galhos ou de terra, os tecidos dos sacos nos quais se vê estampado "União Europeia" ou "USA" servindo de cortina na entrada das tendas.

Esses processos de começo de uma cidade - e começo de uma vida social, econômica, cultural, política inédita - podem ser comparados, por exemplo, ao se passar de um campo de refugiados a uma favela, de um acampamento "autoinstalado" de migrantes "clandestinos", aos antigos acampamentos dos comerciantes itinerantes na África (Dias 2013; Agier 2013). 


\section{Ocupação e favela. A política do acampamento}

Na África e na América Latina, a proporção de urbanização dita "informal" é, como sabemos, muito importante. Nestes contextos, a cidade, caso seja apreendida inteiramente e segundo a igualdade epistemológica defendida mais acima, pode ser descrita como um espaço multiforme e extremamente precário. As palavras bidonville, slum ou favela ressoam por toda parte midiaticamente ou no plano político, mas são inoperantes e mesmo contraproducentes no plano do conhecimento. Trata-se da cidade, mas autoconstruída, do habitat, mas em tábuas de madeira, em toldos plastificados ou de papelão, que se transformará progressivamente utilizando materiais mais sólidos (tijolos, cimento). Ao suspender qualquer julgamento cultural, estético ou social, todas estas formas devem ser consideradas como partes do processo da cidade em contextos de desigualdades.

Diante de algumas grandes favelas ou "complexos" de favelas do Rio de Janeiro, podemos ser levados a comparar e a reconhecer uma forma urbana atualmente conhecida no mundo inteiro por intermédio das mídias e da pesquisa, ou ainda pelas políticas públicas: aquela das "mega-slums", uma forma que compartilham também, por exemplo, os bairros e as zonas denominadas Chalco na periferia da cidade do México, Agua Blanca em Cali, New Bell em Douala, Dharavi em Mumbai e muitas outras ainda. Os termos genéricos que as designam, slum ou bidonville e mais ainda "mega" têm o inconveniente de estigmatizar globalmente a população que ali vive e torná-la muito mais homogênea sociologicamente do que é na realidade. Por outro lado, eles revelam uma forma urbana amplamente disseminada nos países do Sul global. E pode-se pensar que a publicidade que se faz deles os tira um pouco de sua invisibilidade, o que pode contribuir para torná-los objeto de pesquisa e de debate público. ${ }^{8}$ Mas para o pesquisador, nomear e classificar não diz nada, é preciso descrever e compreender os processos cujas formas observamos e que não são senão um momento. É o que eu gostaria de tentar agora, tendo em mente a proposição que guia esta reflexão, a compreensão do fazer-cidade como processo geral ou mesmo universalizável.

A qual cidade a "favela" dá nome? Se a favela é célebre no mundo todo é por designar um processo universal de conquista do espaço. Ela encarna uma modalidade de cidade como movimento. Favelas, slums, bidonvilles: é preciso ao mesmo tempo esquecer e desconstruir as palavras para encontrar o sentido dos processos que elas não fazem senão nomear.

No caso das "invasões" que estão na origem das favelas, ${ }^{9}$ alguém chegou e ocupou um espaço vago. Em seguida, outra pessoa chegou, declarando ser o proprietário ou ter um direito sobre esse espaço e disse: "eu te deixo ocupar 
o espaço com a condição de que a gente entre em acordo sobre isto e aquilo", por exemplo: "vocês serão minha clientela eleitoral!". "Ok, de acordo", respondem os ocupantes, "nós seremos seus eleitores, mas com as seguintes condições etc.". Há uma negociação, mas, para que ela exista, é preciso que em um dado momento alguma coisa tenha acontecido, uma comunidade em movimento, pessoas que chegaram e fizeram o gesto político da ocupação. Compreender o que se passou ali, ao se situar no interior da própria situação, na experiência vivenciada, permite descrever de que modo, em um certo momento, pessoas expressaram uma injustiça, com estas palavras, por exemplo : "nós não somos marginais; temos direito a um alojamento" (slogan do movimento DAL — Direito ao Alojamento, na França), ainda que, uma vez tendo ocupado o espaço, alguém chegue e lhes diga: "vocês são o meu curral eleitoral". A negociação vem após o primeiro movimento, o da ocupação. O que é importante compreender, me parece, é este agir ao mesmo tempo político e urbano: ele marca uma linha de partilha entre antes e depois. Esse movimento é uma tomada do espaço tanto quanto uma tomada da palavra, é o momento político porque é aquele que cria uma situação radicalmente nova. ${ }^{10}$ Eis por que os atores da margem, citadinos sem cidade, ocupam um lugar à parte, precário mas exemplar nos movimentos que fazem a cidade.

\section{A margem e o centro. 0 agir urbano como movimento e desejo}

O fazer-cidade deve ser entendido como um processo sem fim, contínuo e sem finalidade. Ele faz sentido no contexto de uma expansão contínua dos universos sociais e urbanos. Eis por que parece possível elaborar a hipótese teórica (e a aposta política) segundo a qual o fazer-cidade é uma declinação pragmática, aqui e agora, do "direito à cidade", sua instauração. O movimento é essencial nesta concepção da cidade como construção permanente. Uma de suas declinações é o deslocamento. Este último já está presente em outra noção que atravessa toda a proposição do "direito à cidade" de Lefebvre, aquela da centralidade.

O movimento em direção ao centro desde as periferias e os subúrbios ou as "zonas de miséria" é um deslocamento e uma conquista espacial em certa medida. É o que ilustra a interpretação feita por Henri Lefebvre, retomada por David Harvey (2011), da Comuna de Paris de 1871 como uma luta urbana mais que proletária. Pois a Comuna é um "desejo de revanche" e, para alguns, "uma nostalgia do mundo urbano destruído por Haussmann", e ela estabelece uma relação com estratégias de controle e de modernidade (Harvey 2011:14). Para este autor, a centralidade histórica desapareceu 
atualmente, mas há "um impulso em sua direção". Este impulso em direção a uma centralidade virtual encarnada pelo coração vital e pela identidade da cidade, ao mesmo tempo desejo insaciável e movimento infinito da fronteira em direção ao centro, é o motor do agir urbano.

Os debates recentes a propósito do conteúdo e das formas das lutas urbanas ganhariam força se pensassem a cidade a partir de espaços precários da margem. Precariedade, mas exemplaridade do limite, como enfatizamos mais acima. Assim, uma das questões políticas que se colocam na França atualmente é a de saber se é preciso manifestar-se em passeatas e protestos para obter alojamentos decentes para as famílias denominadas "roms", ${ }^{11}$ ou se é preciso defender e reforçar a instalação precária, urbanizá-la, ou seja, torná-la mais habitável, ou mesmo confortável, e assim impor sua existência, sua presença no mundo e na cidade. ${ }^{12}$

Esta questão conduz imediatamente a duas respostas, que se apresentam geralmente em oposição. O que se deve fazer? Manifestar-se nas ruas contra este tratamento de exceção - o "acampamento"13 — que questiona frontalmente o humanismo que reivindicam (em nome do pertencimento às "sociedades democráticas") os mesmos que implementam essa governança urbana de exceção para populações consideradas estrangeiras? Ou ajudar as pessoas que ali estão a ocupar e a habitar o lugar para impor aos fatos sua presença e seu reconhecimento? A alternativa pode não ser uma oposição, mas uma política que se desdobra. É o que ilustra um fato observado na América Latina nos acampamentos urbanos de migrantes, assim como nos antigos campos de refugiados que se urbanizam na África, na Ásia ou no Oriente Próximo: a forma " ocupação " tornou-se mundialmente uma das maneiras para os mais pobres de fazerem reconhecer seu direito a estar ali. A ocupação urbana é um agir político cujo objeto é um direito humano e, ao mesmo tempo, um direito à cidade.

As duas formas são igualmente políticas, mas de modos distintos. O movimento mais radical atualmente, aquele que faz com que ainda exista a questão política do horizonte da cidade, é o que a faz existir não como uma abstração, mas como uma imanência, uma construção em curso e em movimento. Uma política do acampamento que se confunde com a política em geral, no momento em que o mundo em geral se torna cada vez mais urbano, até formar, em breve, uma imensa conurbação.

\section{Conclusão}

A antropologia do fazer-cidade abordada de um ponto de vista social, político e cultural, que quis expressar aqui, permite evidenciar três efeitos 
do agir urbano, que podemos resumir, à guisa de conclusão, da seguinte maneira:

Em primeiro lugar, ele permite a sobrevivência em um distanciamento (um acampamento, uma invasão de um local vazio). É o gesto primeiro da invasão entendida como desobediência e como ilegalidade assumida ainda que o termo invasão seja atualmente considerado "incorreto" pelos meios associativos e acadêmicos, como, por exemplo, em Salvador, onde o termo foi por muito tempo (até os anos 1990) considerado - e ainda continua a ser na linguagem popular - equivalente a "favela", no Rio de Janeiro, e equivalente também a "invasión", em castelhano, utilizado, por exemplo, na Colômbia para designar os setores mais pobres e ilegais das periferias urbanas.

Em segundo lugar, o agir urbano continua na presença recalcitrante sobre o próprio local deste distanciamneto ("eu ficarei aqui, não importa o que haja"), sob a forma mais estabelecida, senão durável, da ocupação.

Em terceiro lugar, o agir urbano opera uma transformação urbana graças a mecanismos duráveis de instalação. Nesta última configuração podem ser destacadas três declinações possíveis a partir de três exemplos quase simultâneos. Na França, o reconhecimento dos acampamentos denominados "roms" como "bidonvilles" é o objeto de uma luta semântica. Esta última é levada a cabo por alguns assistentes socais, associações e pesquisadores, por um lado, que defendem o termo "bidonville" e tendem assim a uma urbanização da "questão rom". Por outro lado, a polícia, os governos distritais e o Ministério do Interior (mas também alguns assistentes sociais, associações e pesquisadores) utilizam os termos "campos" e "acampamentos", geralmente associados a "populações estrangeiras"; neste caso, é o paradigma da segurança e eventualmente humanitário que prevalece. Nesta mesma configuração da instalação e da transformação urbanas, pode-se ainda notar a urbanização dos campos de refugiados ou mesmo a reconstrução urbana planificada de campos de refugiados palestinos destruídos no Líbano (Puig 2014), e por fim no Brasil, a legalização das favelas ou a política chamada de "favela-bairro", que prevaleceu desde a década de 1990 após um longo período de repetidas tentativas de erradicação pelos poderes públicos. ${ }^{14}$

$\mathrm{Na}$ acumulação destes três efeitos de invasão/ ocupação/ instalação encontra-se o movimento do direito à cidade enquanto direito de estar ali e de ali levar uma vida urbana. É neste momento, nesta pragmática, que o fazer-cidade se torna objeto real e observável do "direito à cidade". Para além da necessidade humana de fundação e refundação permanente dos lugares, por mais precários que sejam, esta dinâmica da cidade e do agir urbano mostra o estreito vínculo entre a mobilidade das pessoas e a expansão 
urbana, esta última sendo uma condição para a sedentarização ainda que provisória e da ancoragem local das pessoas em movimento.

Locais, particulares ou precárias, as práticas do fazer-cidade revelam assim uma certa universalidade da cidade, no sentido de que deixam entrever inícios, gêneses, processos e lógicas da cidade, cujo final não conhecemos.

Mas de qual cidade conhecemos o fim? Por mais monumentais, gigantescas, altas, densas, extensas, difusas ou disformes que sejam, todas as cidades bem como todas as localidades estão destinadas à transformação, que é uma forma de seu desaparecimento.

Recebido em 16 de setembro de 2015

Aprovado em 22 de outubro de 2015

Tradução de Roberta Ceva

Michel Agier é antropólogo, directeur d'études na École des Hautes Études en Sciences Sociales (EHESS) e pesquisador no Institut de Recherches pour le Développement (IRD). E-mail: <michel.agier@ehess.fr>

\section{Notas}

* Este artigo é a versão escrita e aumentada da conferência "Da etnografia das margens à antropologia da cidade", proferida em 17 de outubro de 2014, no Colégio Brasileiro de Altos Estudos (CBAE/UFRJ), no quadro do programa da cátedra francesa do consulado da França na UERJ (Departamento de Antropologia). Eu agradeço a Peggy Scremin (consulado da França), Patricia Birman (UERJ) e José Sergio Leite Lopes (CBAE) por esta oportunidade.

${ }^{1}$ Ver Claude Lévi-Strauss (1955). Yves Hersant (1999) a ele se refere na introdução ao dossiê "Lumières sur la ville". José Guilherme Magnani (1999) dedica um estudo à relação de Claude Lévi-Strauss com as cidades, particularmente brasileiras e indianas. Ver também M. Agier (2011).

${ }^{2}$ Ver particularmente Gérard Althabe (1990) e Althabe, Marcadet, de La Pradelle e Sélim (1986). Na mesma perspectiva, ver igualmente de La Pradelle e Sélim (2000). Mais recentemente, ver Lallement (2015).

${ }^{3}$ Ver também Mongin (2005). 
${ }^{4}$ Ver Françoise Choay (2006), particularmente os textos reunidos na segunda parte da obra, "O urbano", pp. 129-251. Entre as várias obras sobre a violência da segregação urbana, ver os trabalhos já clássicos de Teresa Caldeira (2000) sobre São Paulo e de Mike Davis (1990) sobre Los Angeles.

${ }^{5}$ Para uma apresentação do descentramento como postura epistemológica e não culturalista, ver Agier (2015).

${ }^{6}$ Ver Michel Agier e Sara Prestianni (2011). No caso do Brasil, ver o trabalho pioneiro de Lygia Sigaud (2000).

${ }^{7}$ [N.T.]: Alto Comissariado das Nações Unidas para os Refugiados.

${ }^{8}$ Para apresentações comparativas em escala regional ou global, ver Saglio-Yatzimirsky e Landy (orgs.) (2013); Davis (2006); Simone (2004).

9 "Invasão" é o termo utilizado em Salvador, Bahia, para designar o que no Rio e em outros lugares denomina-se "favela". Conservo este vernáculo, observando (retornarei a este ponto mais adiante) que o termo voluntariamente utilizado há alguns anos pelas associações da Bahia não é mais "invasão", mas "ocupação".

${ }^{10}$ Jacques Rancière situa neste acontecimento preciso o momento constituinte da política (1995).

${ }^{11}$ [N. T.] "Rom" designa, na França, famílias de migrantes oriundas da Romênia ou da Bulgária e consideradas "nômades" em função de sua origem e cultura historicamente comuns (ditos "ciganos" no Brasil).

${ }^{12}$ Ver a obra Considérant qu'il est plausible que de tels événements puissent à nouveau survenir (organizada por Sébastien Thiery, 2014b), obra coletiva e manifesto organizado pela associação Perou após a destruição do acampamento denominado "rom" de Ris-Orangis em abril de 2013. Ver igualmente Olivera (2011).

${ }^{13}$ Ver Michel Agier, "L'encampement du monde" (2014b).

${ }^{14}$ Esta inserção e esta estabilização do sujeito urbano outro, vindo da margem, no tecido da cidade levam a outras questões e problemáticas relativas ao controle dos espaços urbanos, das economias, das trocas e dos modos de vida na cidade. É o que ocorre atualmente nas políticas ditas de "pacificação" nas maiores cidades brasileiras. 


\section{Referências bibliográficas}

AGIER, Michel. 2011. Antropologia da cidade. Lugares, situações, movimentos. São Paulo: Editora Terceiro Nome. - 2013. Campement urbain. Du refuge naît le ghetto. Paris: Payot.

- (org.). 2014a. Un monde de camps. Paris: La Découverte.

_. 2014b. "L'encampement du monde". In: M. Agier (org.), Un monde de camps. Paris: La Découverte. pp. 11-28.

- 2015. Migrações, descentramento e cosmopolitismo. Uma antropologia das fronteiras. São Paulo/ Maceió: Unesp/ Ufal.

- \& PRESTIANNI, Sara. 2011. Je me suis réfugié là! Bords de route en exil. Paris: Éditions Donner Lieu.

ALTHABE, Gérard. 1990. "Ethnologie du contemporain et enquête de terrain". Terrain, Carnets du Patrimoine Ethnologique, 14:126-131.

; MARCADET, Christian; LA PRADELLE, Michèle de \& SÉLIM, Monique. 1993. Urbanisation et enjeux quotidiens. Terrains ethnologiques dans la France actuelle. Paris: L'Harmattan.

AUGE, Marc. 1992. Non-lieux. Paris: Seuil.

BAILLY, Jean-Christophe. 2013. La phrase urbaine. Paris: Seuil.

BAZIN, J. 1996. "Interpréter ou décrire. Notes critiques sur la connaissance anthropologique". In : J. Revel \& N. Wachtel (eds.), Une école pour les sciences sociales. Paris: Cerf/EHESS. pp. 401-420.

CALDEIRA, Teresa. 2000. City of walls: crime, segregation, and citizenship in São Paulo. Los Angeles: University of California Press.

CHOAY, Françoise. 2006. Pour une anthropologie de l'espace. Paris: Seuil.

DAVIS, Mike. 2006. Planet of slums. Londres: Verso.
. 1997 [1990]. City of quartz. Los Angeles, capitale du futur. Paris: La Découverte. DIAS, Amanda. 2013. Aux marges de la ville et de l'État. Camps palestiniens et favelas cariocas. Paris: Karthala.

DONZELOT, J. 2009. "La nouvelle question urbaine". In: La ville à trois vitesses, et autres essais. Paris: Éditions de La Villette. pp. 29-52.

GRAFMEYER, I. Joseph (orgs.). 1980. L'École de Chicago. Naissance de l'écologie urbaine. Paris: Aubier.

HARVEY, David. 2011. Le capitalisme contre le droit à la ville. Néolibéralisme, urbanisation, résistances. Paris: Éditions Amsterdam.

HERSANT, Yves. 1999. "Lumières sur la ville". Le genre humain, 34 .

LALLEMENT, Emmanuelle. 2015. “Ethnologists of the city: history of an object and of disciplines". In: Sophie Chevalier (org.), Anthropology at the crossroads: the view from France. Londres: Sean Kingston Publishing.

LA PRADELLE Michèle de. 2000. "La ville des anthropologues". In: Th. Paquot; M. Lussault \& S. Body-Gendrot (orgs.), La ville et l'urbain. Etat des savoirs. Paris: La Découverte. pp. 47-56.

LEFEBVRE, Henri. 1970. La révolution urbaine. Paris: Gallimard. - 2009. Le droit à la ville. Paris: Economica/Anthropos.

LÉVI-STRAUSS, Claude. 1955. Tristes tropiques. Paris: Plon.

MAGNANI, José Guilherme Cantor. 1999. "As cidades de Tristes Trópicos". Revista de Antropologia , 42(1-2):97-111.

MAZZITELLI, Adriana Goni. 2012. "Rome: l'immigration au secours de la ville éternelle". Trad. Agnès Sander). Métropolitiques, 25. Disponível em: http://www.metropolitiques.eu/Rome- 
limmigration-au-secours-de.html. Acesso em: 16/08/2015.

MONGIN, Olivier. 2005. La condition urbaine. La ville à l'heure de la mondialisation. Paris: Seuil.

OLIVERA, Martin. 2011. Roms en (bidon-) ville. Paris: ENS Éditions.

PUIG, Nicolas. 2014b. "Nahr al-Bared (Liban). Le camp et ses doubles". In: M. Agier (org.), Un Monde de camps. Paris: La Découverte. pp. 211-229.

RANCIÈRE, Jacques. 1995. La mésentente. Paris: Galilée.

SAGLIO-YATZIMIRSKY, Marie-Caroline \& LANDY, Frédéric (orgs.). 2013. Megacity slums: social exclusion, space and urban policies in Brazil and India. Londres: Imperial College Press.

SIGAUD, Lygia. 2000. "A forma acampamento: notas a partir da versão pernambucana". Novos Estudos Cebrap, 58: 73-92.

SIMONE, Abdumaliq. 2004. For the city yet to come. Changing African life in four cities. Durham: Duke University Press, pp. 251-277.

THIERY, Sébastien. 2014. Considérant qu'il est plausible que de tels événements puissent à nouveau survenir. Paris: Post-Éditions.

WIRTH, Louis. 1984 [1938]. "Le phénomène urbain comme mode de vie". In: Yves Grafmeyer \& Isaac Joseph (orgs.), L'école de Chicago. Paris: Aubier. 


\section{Resumo}

Neste artigo, proponho definir a antropologia da cidade como a exploração etnográfica e a compreensão reflexiva das situações, dos lugares e dos movimentos que "fazem cidade". Fazer-cidade é o meio para a instauração do "direito à cidade", aqui e agora. De acordo com esta concepção, algumas práticas polêmicas ou eventualmente minoritárias (invasões, ocupações) ganham um sentido radical de um ponto de vista teórico, pois fazem nascer - a partir das margens, das fronteiras, do precário, do vazio e da desordem um desejo e um apelo em direção a um horizonte de cidade sonhada, virtual ou ideal. O movimento do fazer-cidade é incitado por uma ausência (ao se afirmar que "a cidade está morta") e impulsionado por uma imagem, um mito perdido, um horizonte ainda que inatingíveis. Neste contexto e segundo um princípio geral de relatividade, a antropologia da cidade não produz nem se refere a nenhuma definição normativa da cidade em si, mas a concebe como o movimento contínuo de sua construção e desconstrução.

Palavras-chave Cidade, Margens, Acampamentos, Favelas.

\section{Abstract}

In this article, I define the anthropology of the city as an ethnographic exploration and reflexive understanding of the situations, places and movements that "make the city". City-making is the means for the instauration of the "right to the city" in the here and now. According to this view, certain polemical or, perhaps, minority practices (invasions, occupations) attain a radical sense from a theoretical point of view, since they give birth - from the edges, the frontiers, the precarious, the empty and the disorder - to a desire and a demand for a dream city, whether virtual or real. The movement of city-making is incited by an absence (in the claim that "the city is dead") and driven by an intangible image, a lost myth, a horizon. In this context, and according to a general principle of relativity, the anthropology of the city neither produces nor refers to any normative definition of the city per se, but conceives it as the continuous movement of its own construction and deconstruction.

Key words City, Edges, Camps, Favelas. 